\title{
Influence of Carbonitriding Conditions on Phase Composition and Residual Stresses for 20MnCr5 Low Alloy Steel
}

\author{
Richard J Katemi ${ }^{{ }^{*}}$ and Jeremy Epp ${ }^{2,3}$ \\ ${ }^{I}$ University of Dar es Salaam, School of Mines and Geosciences, Department of Mining and \\ Mineral Processing Engineering, P. O. Box 35131, Dar es Salaam, Tanzania \\ ${ }^{2}$ Leibniz-Institute for Materials Engineering-IWT Bremen, Badgasteiner Str. 3, 28359 Bremen, \\ Germany \\ ${ }^{3}$ MAPEX Center for Materials and Processing, University of Bremen, Badgasteiner Str. 3, 28359 \\ Bremen, Germany \\ *Corresponding author.Email: rkatemi@gmail.com \\ Received 23 Mar 2021, Revised 25 May 2021, Accepted 26 May 2021, Published May 2021 \\ DOI: https://dx.doi.org/10.4314/tjs.v47i2.34
}

\begin{abstract}
This paper reports an investigation of the influence of carbonitriding conditions for $20 \mathrm{MnCr} 5 \mathrm{low}$ alloy steel. Three gaseous carbonitriding conditions were investigated based on different carbon and nitrogen potentials to attain varying levels of carbon between 0.62 and $0.93 \%$ mass, whereas for nitrogen between 0.19 and $0.26 \%$ mass at the surface. Analysis of retained austenite and residual stress distributions was conducted using X-ray diffraction technique. The effective case depth varied between 900 and $1200 \mu \mathrm{m}$. The case microstructures were characterized by varying proportions of retained austenite and martensite, while the core contained essentially bainitic microstructures. The maximum amount of retained austenite which occurred at a depth of $50 \mu \mathrm{m}$ from the subsurface ranged between 30 and $70 \%$ mass and significantly influenced the level of surface micro-hardness whereas the core hardness remaining relatively constant at $450 \mathrm{HV} 1$. High values of residual stresses in martensite phase were observed. The signs, magnitudes, distributions and location of maximum compressive residual stresses were highly influenced by the maximum fraction of retained austenite. Retained austenite of 30\%, 50\% and 70\% mass at the surface lead to peak compressive residue stresses of $-280,-227$, and $-202 \mathrm{MPa}$ at depths of 555,704 , and $890 \mu \mathrm{m}$, respectively.
\end{abstract}

Keywords: Carbonitriding, retained austenite, martensite, residual stress, XRD.

\section{Introduction}

The application, performance and reliability of power transmission components such as gear, bearing and shaft, highly depend on mechanical properties of the surface. For such components, a hard surface is needed to resist wear and improve fatigue limit while the core of such components remaining soft and tough. However, low alloy steel grades such as $20 \mathrm{MnCr} 5$ and $18 \mathrm{CrNiMo7}-6$, which are commonly employed in manufacturing of such machine parts cannot be directly applied due to low surface hardness and poor resistance to wearing. Carburizing, nitriding and carbonitriding are some of the thermochemical treatments used to improve the surface hardness, resistance to wearing and toughness of the core.

The carbonitriding treatment, which is considered as the modified form of carburizing process, involves simultaneous diffusion of carbon and nitrogen atoms into the interstitial sites of austenite at high temperatures in the range of 850 to $940{ }^{\circ} \mathrm{C}$. The advantages of 
carbonitriding over carburizing process arise from the presence of nitrogen that leads to improved hardenability, resistance to wear and softening at elevated service temperature, higher fatigue limits and low operating costs because of lower temperatures and shorter cycle time involved (Herring 2011). Substantial work has been carried out to investigate the effects of gaseous composition and control of the carbonitriding atmosphere by Davies and others (Davies and Smith 1978, Winter 2013). Further, nearly all the available information on residual stresses belongs to martensite/bainite phase resulting from carburizing treatment (Chongkim 1982). This is not the case when it comes to the effects of carbonitriding conditions on the phase compositions, magnitudes and distribution of residual stresses in retained austenite and martensite phase. It is evident that the varying fractions of retained austenite can significantly influence the magnitudes and distribution of residual stresses due to differences in the level of volumetric expansion between the subsurface and the core.

This work investigated the influence of carbonitriding conditions on phase compositions, magnitudes and distribution of residual stresses in $20 \mathrm{MnCr} 5$ low alloy steel. Three carbonitriding conditions designated as $\mathrm{CN} 1, \mathrm{CN} 2$, and CN3 with different carbon and nitrogen potentials were carried out. The carbon or nitrogen potential is the maximum carbon or nitrogen content a steel grade can absorb or accommodate during thermochemical treatment in the absence of other alloying elements. The evaluated properties include chemical compositions, phase composition, hardness and residual stresses. Analysis of phase composition and residual stresses was carried using X-Ray diffraction.

\section{Materials and Methods \\ Materials and carbonitriding treatments}

The material used in this investigation was $20 \mathrm{MnCr} 5$ low alloy steel with ferrite/pearlite initial microstructures. The material was obtained from the Institute of Material Science (Leibniz-Institut fur Werkstofforientierte Technologien - IWT Bremen) at the University of Bremen. Optical Emission Spectroscopy (OES) was used to determine the initial chemical composition of the as-received material and given in Table 1. A similar technique was used for analysis of carbon and nitrogen depth profiles of the carbonitrided samples. Disc samples with a diameter of 24 $\mathrm{mm}$ and a thickness of $8 \mathrm{~mm}$ were machined from the as-received steel rod bar of $25 \mathrm{~mm}$ diameter.

Table 1: Initial chemical composition of 20MnCr5 low alloy steel determined by OES

\begin{tabular}{lllllllllll}
\hline Elements & $\mathrm{C}$ & $\mathrm{Si}$ & $\mathrm{Mn}$ & $\mathrm{P}$ & $\mathrm{S}$ & $\mathrm{Cr}$ & $\mathrm{N}$ & $\mathrm{Ni}$ & $\mathrm{Al}$ & $\mathrm{Fe}$ \\
\hline Mass.-\% & 0.208 & 0.178 & 1.380 & 0.012 & 0.022 & 1.076 & 0.017 & 0.14 & 0.026 & $\mathrm{Bal}$ \\
\hline
\end{tabular}

The samples were then subjected to a carbonitriding treatment consisting of a boost and diffusion stage. Three carbonitriding treatments designated as $\mathrm{CN} 1, \mathrm{CN} 2$ and $\mathrm{CN} 3$ were conducted. In each treatment, the boost stage which enhances diffusion rate of interstitial carbon and nitrogen atoms was carried at $940{ }^{\circ} \mathrm{C}$, carbon potential of $1.2 \%$ mass and ammonia enrichment of 10 vol.- $\%$. During the diffusion stage the temperature was held at $850{ }^{\circ} \mathrm{C}$ with different carbon potential and ammonia enrichment rates as indicated in Table 2. After carbonitriding process, samples were quenched into oil held at $60{ }^{\circ} \mathrm{C}$ for 15 minutes.

Table 2: Carbonitriding treatment conditions during diffusion stage

\begin{tabular}{llll}
\hline S/No & Temperature $\left[{ }^{\circ} \mathrm{C}\right]$ & Carbon potential $[\% \mathrm{C}]$ & $\mathrm{NH}_{3}$ addition $\left[\% \mathrm{NH}_{3}\right]$ \\
\hline $\mathrm{CN} 1$ & 850 & 0.60 & 1 \\
$\mathrm{CN} 2$ & 850 & 0.80 & 2 \\
$\mathrm{CN} 3$ & 850 & 0.94 & 2 \\
\hline
\end{tabular}


Katemi and Epp - Influence of carbonitriding conditions on phase composition ...

Microstructure and micro-hardness analysis

Metallographic acquisition was done using optical metallurgical microscope after mechanical polishing using silica paper to obtain a mirror surface followed by chemical etching using a $3 \%$ alc. $\mathrm{HNO}_{3}$ for $40 \mathrm{sec}$. The microhardness of the carbonitrided samples were measured using a micro-hardness tester HMV2MCL2 according to DIN50190/1German Standard. The measurement was carried out in a Vickers press mode with a press force of $1000 \mathrm{p}$ applied for 15 seconds.

\section{Phase composition and residual stress analysis}

The acquisition of diffraction patterns for phase composition and residual stresses analysis was done using an MZ VI E (GE Inspection Technology) diffractometer (Figure 1) equipped with a Position Sensitive Detector. Chromium $(\mathrm{Cr}-\mathrm{K} \alpha)$ radiations $\left(\lambda_{\alpha 1}=2.28975\right.$ $\AA$ A) produced by a standard sealed X-ray tube operated at $33 \mathrm{kV}$ and $40 \mathrm{~mA}$ were used. The primary beam was defined by a collimator with $2 \mathrm{~mm}$ in diameter and vanadium was used as a filter for $\mathrm{Cr}-\mathrm{K}_{\beta}$ radiations. For phase analysis, the scan range was from $60^{\circ}$ to $164^{\circ} 2 \theta$ with a scan step size of $0.050^{\circ} 2 \theta$ and scan speed of 0.658 steps per second. Typical X-ray diffraction patterns as the function of depth from the surface are given in Figure 2 . Analysis of patterns was performed using Rietveld Method (Topas 4.2, Bruker Axs) (Young 1993) considering the fundamental parameter refinement approach (FPA). A NIST $\mathrm{LaB}_{6}$ reference powder was measured to determine the instrumental contribution on the diffraction patterns.

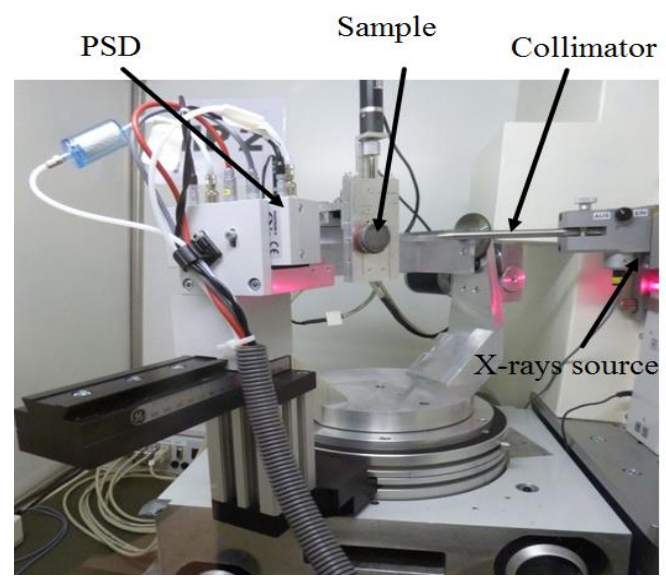

Figure 1: XRD MZ VI E (GE Inspection Technology) employed for acquisition of both phase and residual stress diffraction patterns.

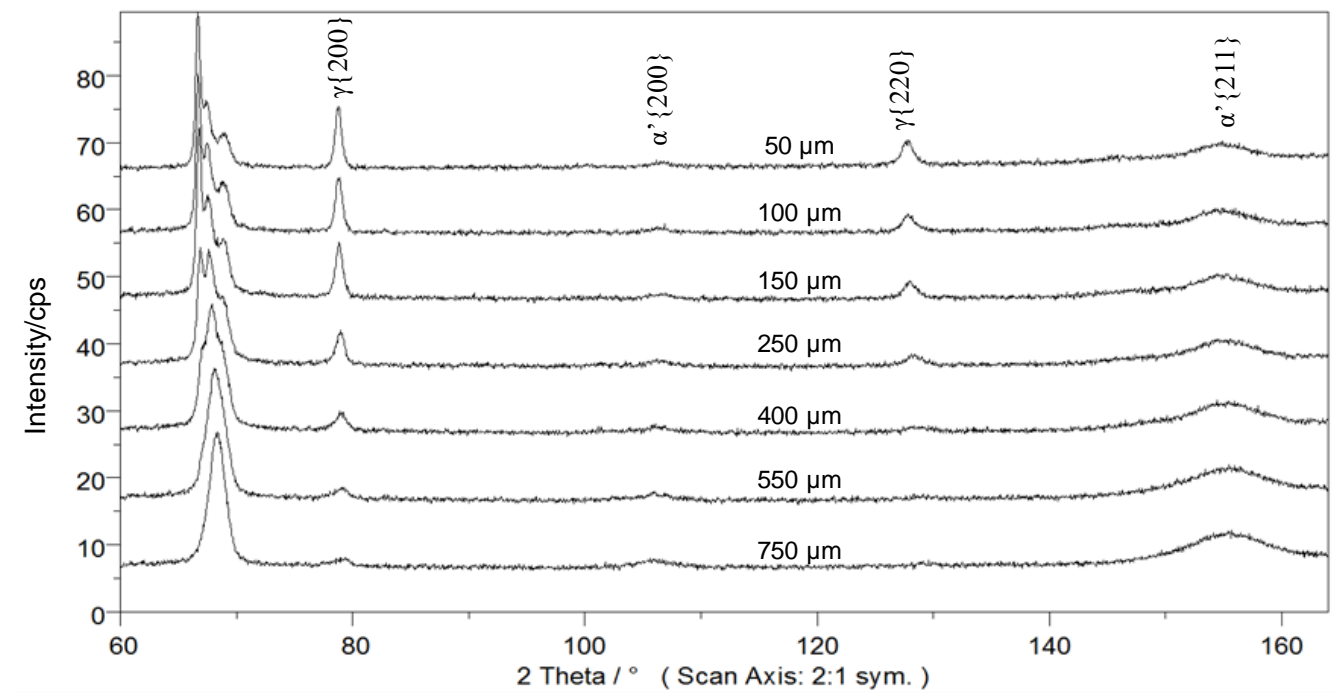

Figure 2: X-ray diffraction patterns as a function of depth (top) for $\mathrm{CN} 3$ after carbonitriding and tempering treatment $\left(\gamma-\right.$ austenite phase, $\alpha^{\prime}-$ martensite phase). 
The measurement of residual stresses for martensite phase was performed using peak $\alpha^{\prime}\{211\}$. The measurements of residual stresses were conducted in both as-quenched and tempered states. Details of the acquisition parameters including the tilt angle, scan speed and scan range were according to Katemi et al. (2014a). A typical example of the collected diffraction patterns for stress analysis is given in Figure 3. Analysis of these diffraction patterns was done considering the Standard $\operatorname{Sin}^{2} \psi$ Method which assumes no macroscopic stress $\left(\sigma_{33 \text { macro }}=0\right)$ perpendicular to the plane surface. The peak position was determined by average gravity method after smoothing and linear background correction. The Young's modulus and Poisson coefficient were $220 \mathrm{GPa}$ and 0.28, respectively (Eigenmann and Macherauch 1996).

The residual stress depth distribution was established after a successive layer removal by electro-polishing, which is essential to avoiding introduction of residual stresses due to mechanical polishing. The electro-polishing was carried out using an electrolyte solution containing $80 \% \quad \mathrm{H}_{3} \mathrm{PO}_{4}$ and $20 \% \mathrm{H}_{2} \mathrm{SO}_{4}$. Low current setting was used to enable a smooth surface and avoid heating of the solution and the sample, which in turn could lead to microstructural changes and residual stress relaxation. Correction of residual stresses due to layer removal was performed according to Moore and Evans (Totten et al. 2002).

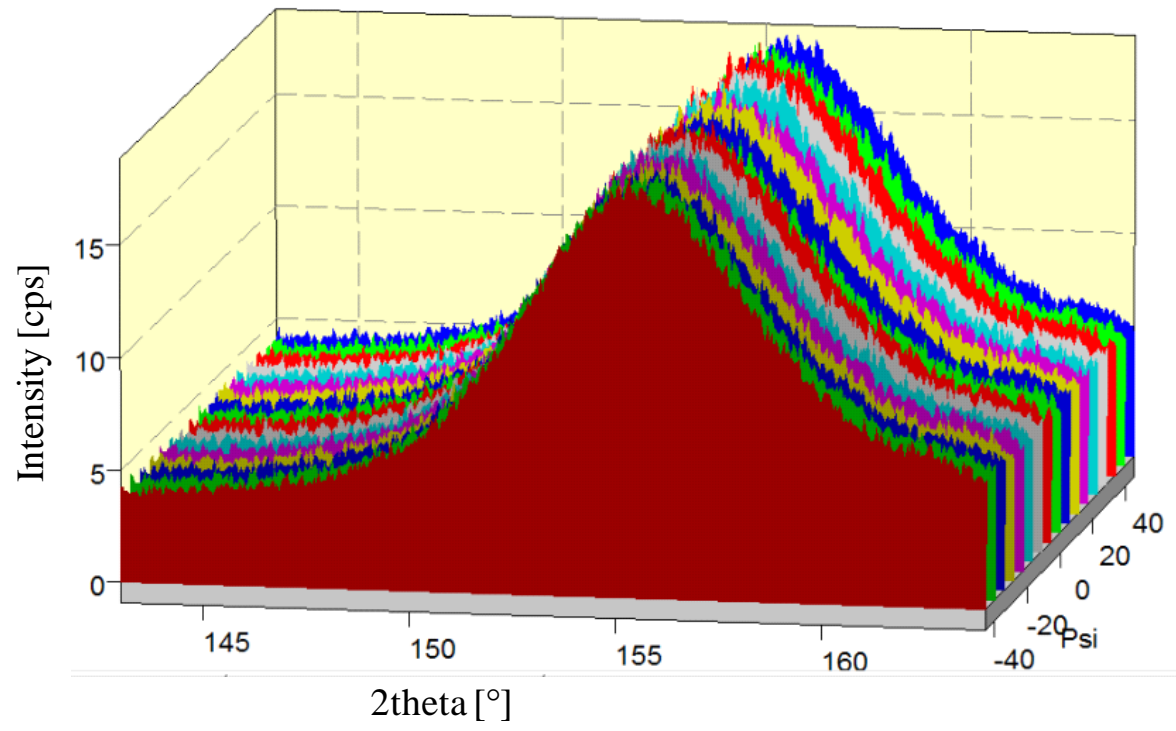

Figure 3: Typical examples of residual stress diffraction patterns for martensite $\alpha^{\prime}\{211\}$.

Results and Discussions

\section{Carbon and nitrogen depth profiles after} carbonitriding

Figure 4 provides the carbon and nitrogen depth profiles for carbonitriding conditions $\mathrm{CN} 1, \mathrm{CN} 2$ and $\mathrm{CN} 3$ determined by OES. The maximum concentrations of carbon contents which occur at a depth of $50 \mu \mathrm{m}$ from the surface range between 0.6 and 0.92 mass. $-\%$, whereas that of nitrogen range between 0.18 and 0.26 mass. $-\%$. The maximum concentration of carbon content reached is highly dependent on the carbon potential of the carbonitriding atmosphere and increases with increasing carbon potential. Such influence of carbon and nitrogen potentials on the maximum concentration of carbon/nitrogen content at the surface have been observed in the previous work of the authors (Katemi et al. 2014b). 


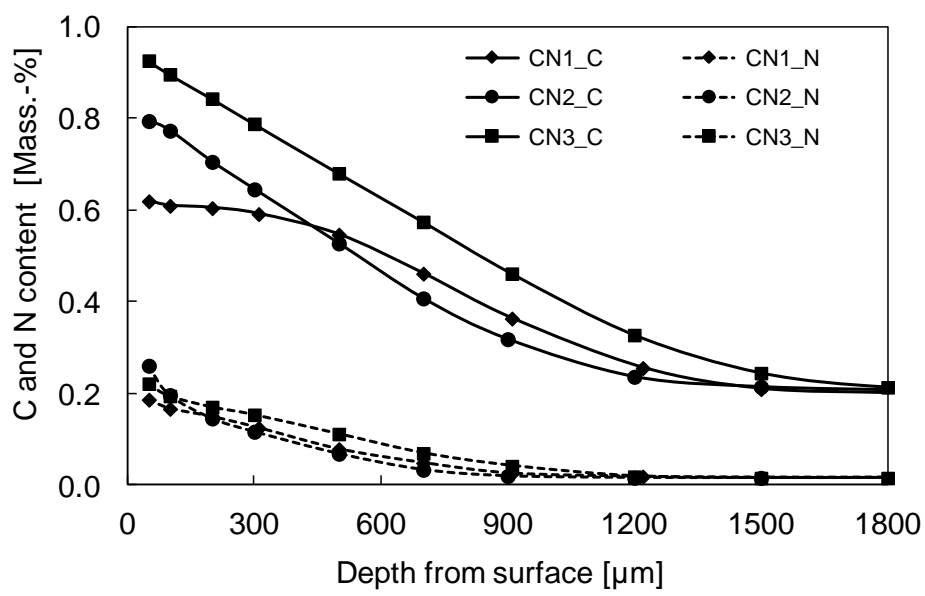

Figure 4: Carbon and nitrogen depth profiles for the three-carbonitriding conditions $(\mathrm{CN} 1, \mathrm{CN} 2$, CN3).

\section{Microstructures and micro-hardness}

Figure 5 presents the tempered case and core microstructures of carbonitrided $20 \mathrm{MnCr} 5$ low alloy steel specimens revealed after etching with $3 \%$ alc. $\mathrm{HNO}_{3}$ for 30 seconds. The case microstructures are characterized by plate martensite (dark), retained austenite (white) and finely disseminate precipitates. A clear difference in the fraction of retained austenite (white matrix) among the various carbonitriding conditions can be observed and increases with increasing carbon potential of the carbonitriding atmosphere. Furthermore, case microstructures are characterized by subsurface grain boundary oxidations in the first $20 \mu \mathrm{m}$ from the surface. This is mainly due to the oxidation effect of some alloying elements (mainly $\mathrm{Mn}, \mathrm{Cr}$ and $\mathrm{Si}$ ) which is considered to be normal for carbonitriding/carburizing treatment carried out in endothermically generated atmospheres (Sastry et al. 1982). The oxidation of subsurface microstructures necessitates finish grinding and is considered to have minor negative effect on bending fatigue, and a positive effect on contact fatigue (Parrish 1999). On the other hand, the core is characterized by bainitic microstructure. 

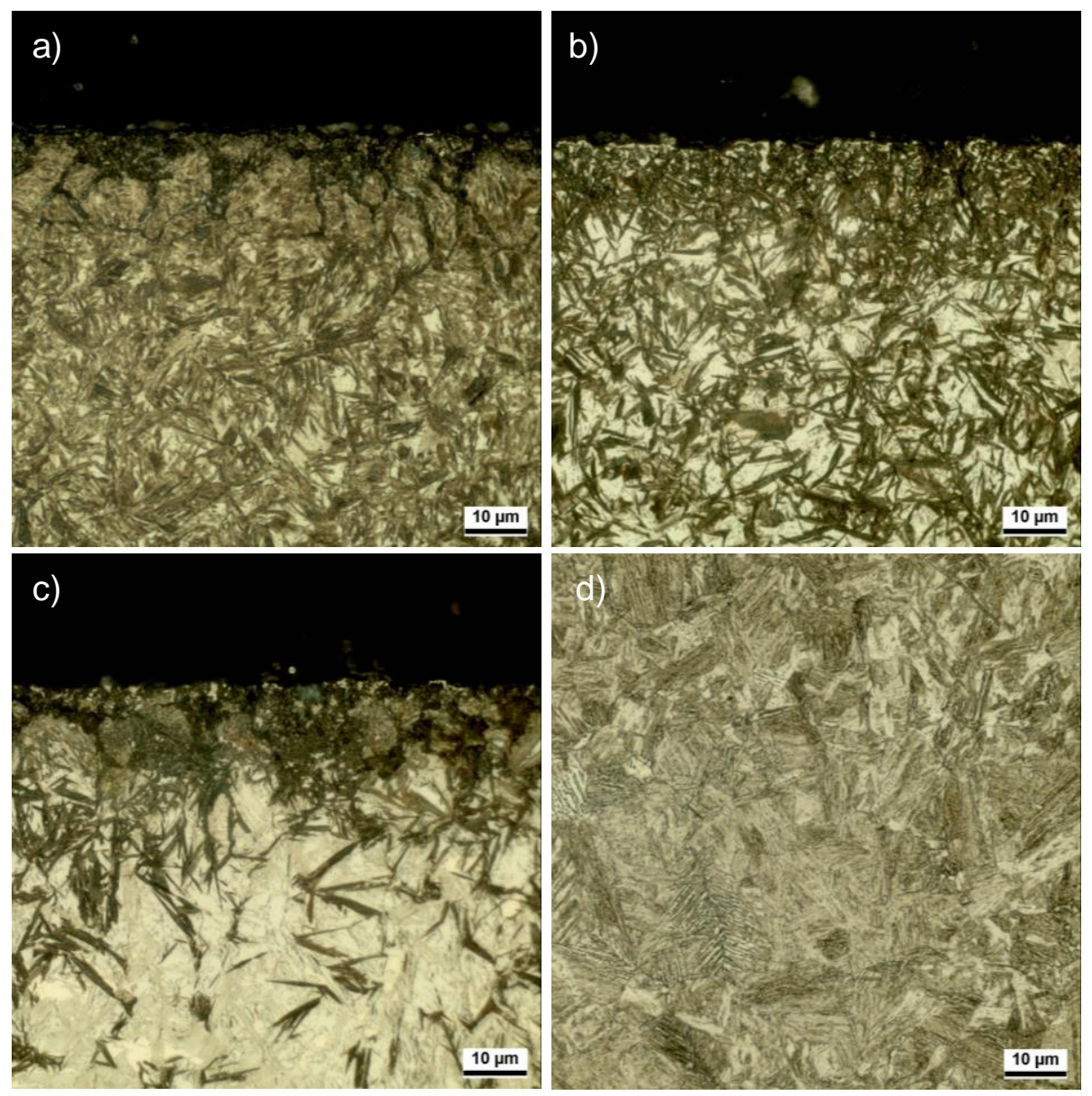

Figure 5: Tempered case microstructure after carbonitriding treatments: a) CN1, b) CN2, c) CN3, and d) core microstructure.

Figure 6 shows the micro-hardness depth profiles for the three carbonitriding conditions after tempering at $170{ }^{\circ} \mathrm{C}$ for 2 hours. As observed from this figure the maximum microhardness value which occurs in the range between $200 \mu \mathrm{m}$ and $500 \mu \mathrm{m}$ from the surface, varies between 700 and $730 \mathrm{HV} 1$ with an effective case depth ranging between 930 and $1200 \mu \mathrm{m}$. The presence of retained austenite in the subsurface surface lowers the hardness level. For example, at a depth of $50 \mu \mathrm{m}$ from the fractions of retained austenite are 31,52 , and 68 mass. $-\%$ for $\mathrm{CN} 1, \mathrm{CN} 2$, and $\mathrm{CN} 3$, 641, and $564 \mathrm{HV} 1$, respectively. It is obvious from the figure that the location of maximum hardness value is highly dependent on the maximum fraction of retained austenite at the surface and it increases with increasing retained austenite content. The hardness of the core is independent of the carbonitriding conditions and remains relatively constant at $450 \mathrm{HV} 1$. Such consistence of core-hardness value, which is linked to the type of bainitic microstructures, has been reported by Katemi and Epp (2019). 


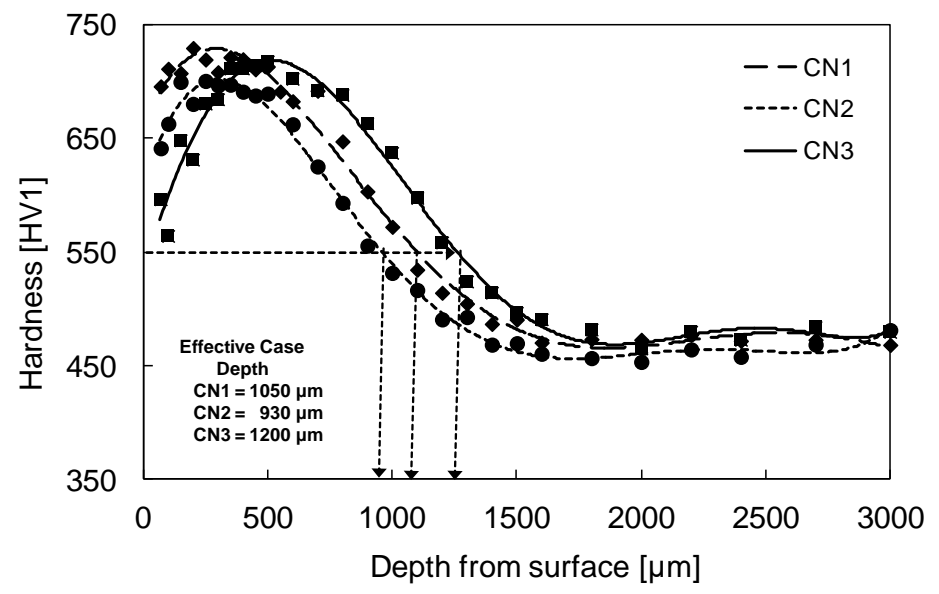

Figure 6: Microhardness distribution embedded on case-microstructures.

\section{Retained austenite distributions}

Figure 7 provides the variation of retained austenite as function of depth for the three carbonitriding conditions. As can be observed from the figure, the maximum retained austenite which occurs at a depth of $50 \mu \mathrm{m}$ from the surface, ranges between 30 and $70 \%$ mass. These are the values of austenite, which remain untransformed during quenching process at $60{ }^{\circ} \mathrm{C}$. The highest value and distribution of retained austenite depth correlate well with the variations of carbon and nitrogen contents as illustrated in Figure 4, which in turn depend on the carbon and nitrogen potentials. In the first 50 microns, small fractions of retained austenite were observed. Such small fractions retained austenite are attributed to oxidation and precipitates formation, which lead to less carbon/nitrogen atoms in solid solution during martensitic transformation. The low carbon/nitrogen content in solution increases the martensite start temperature (Ms) and promotes formation of high temperature transformation products such bainite and pearlite. Similar observations of small fractions of retained austenite in the first $50 \mu \mathrm{m}$ have been reported in the work of Katemi et al. (2014b).

A comparison between Figure 6 and Figure 7 for the three-carbonitriding conditions indicates that as the maximum retained austenite, which occurs at a depth of $50 \mu \mathrm{m}$ from the surface, increases the micro-hardness at the same depth decreases while the maximum micro-hardness value remaining relatively constant at about $700 \mathrm{HV}$. 


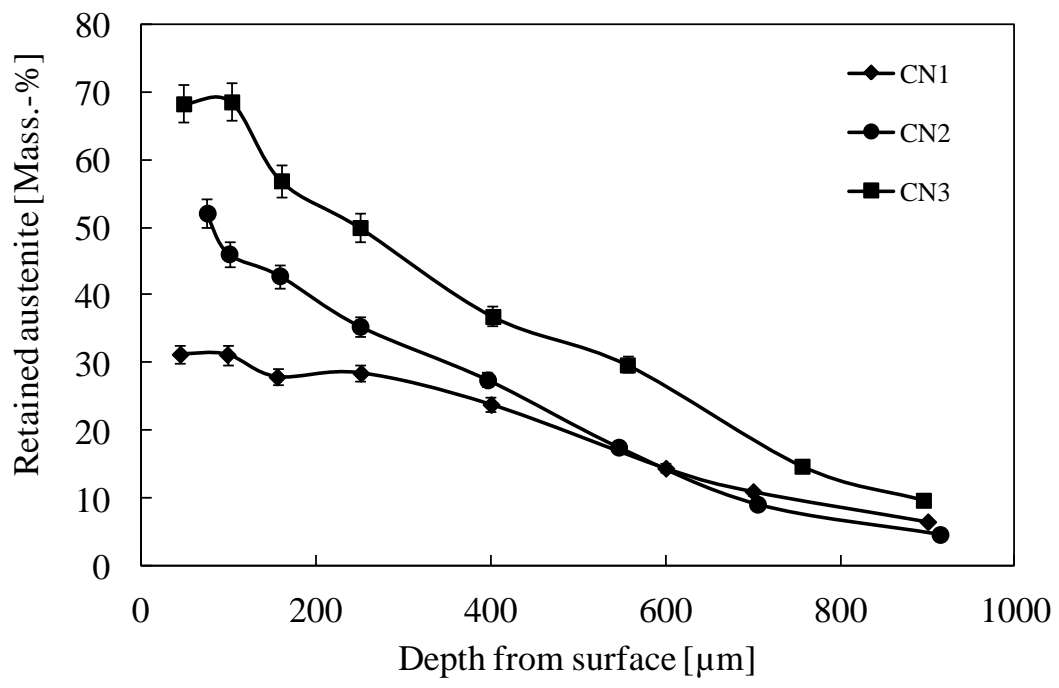

Figure 7: Variation of retained austenite as function of depth from the surface.

\section{Residual stress distributions}

Figure 8 shows the biaxial residual stress $\left(\sigma_{33}=0\right)$ depth distributions martensite phase for the three carbonitriding conditions $(\mathrm{CN} 1$, $\mathrm{CN} 2$, and $\mathrm{CN} 3$ ) in as-quenched state. In all cases, martensite phase is in compressive state. In the first $200 \mu \mathrm{m}$ from the surface, martensite is characterized by less compressive residual stress (RS) ranging between $-120 \mathrm{MPa}$ for $\mathrm{CN} 1$ and $-50 \mathrm{MPa}$ for $\mathrm{CN} 3$. In this range, compressive RS in martensite phase is considerably affected by the fraction of retained austenite and compressive RS decreases with increasing retained austenite content.

In the range between $200 \mu \mathrm{m}$ and the case/core interface, martensite phase is characterized by peak compressive residual stresses. As can be observed from Figure 8, the peak compressive RS values are about -280 $\mathrm{MPa}$ at a depth of $555 \mu \mathrm{m},-227 \mathrm{MPa}$ at a depth of $704 \mu \mathrm{m}$, and $-200 \mathrm{MPa}$ at a depth of $890 \mu \mathrm{m}$ for $\mathrm{CN} 1, \mathrm{CN} 2$, and $\mathrm{CN} 3$, respectively. From these data, it is sufficient to suggest that the increase in fractions of retained austenite in the subsurface does not only reduce the peak compressive residual stress, but also shifts the location of peak compressive RS towards the case/core interface. In all cases, the location of peak compressive residual stress lies in the range of 40 to $60 \%$ of the total case depth $(\approx$ $1500 \mu \mathrm{m}$ ) where the proportion of martensite to austenite is about $80 \%$. The peak compressive RS values obtained in this work are in the same range as the peak compressive RS values observed in previous studies (Davis and Associates 2002). 


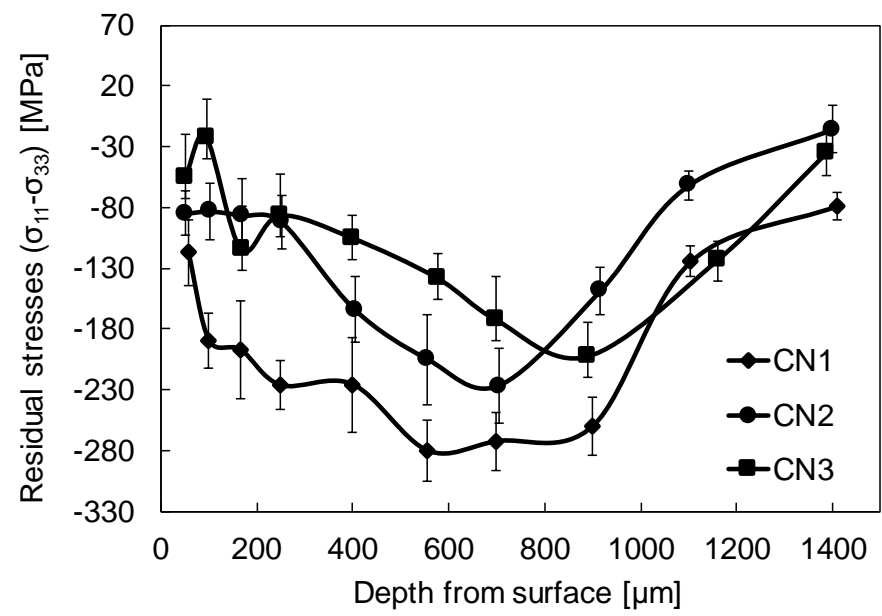

Figure 8: Residual stress distributions after carbonitriding treatment (as-quenched state) for three carbonitriding conditions.

Figure 9 presents the magnitudes and distribution of residual stresses in martensite phase after tempering at $170{ }^{\circ} \mathrm{C}$ for 2 hours for $\mathrm{CN} 1, \mathrm{CN} 2$, and $\mathrm{CN} 3$ carbonitriding conditions. Comparing to the magnitude of RS observed in Figure 8, tempering process relaxes significantly the compressive RS and alters the distributions of residual stresses. Relaxation of up to $210 \mathrm{MPa}$ for $\mathrm{CN} 1,108 \mathrm{MPa}$ for CN2, and $122 \mathrm{MPa}$ for $\mathrm{CN} 3$ are reached. The RS relaxation is attributed to re-organization of thermally activated dislocations as well as movements of interstitial carbon and nitrogen atoms toward the area of high dislocation density and grain boundaries (Mittemeijer et al. 1986). The low relaxation effects in $\mathrm{CN} 2$ and $\mathrm{CN} 3$ can be attributed to the high amount of thermally stabilized retained austenite $(>50 \%$ mass) in comparison to that in $\mathrm{CN} 1$ (20\% mass). Moreover, the tempering process slightly shifts the location of peak compressive RS towards the case/core interface.

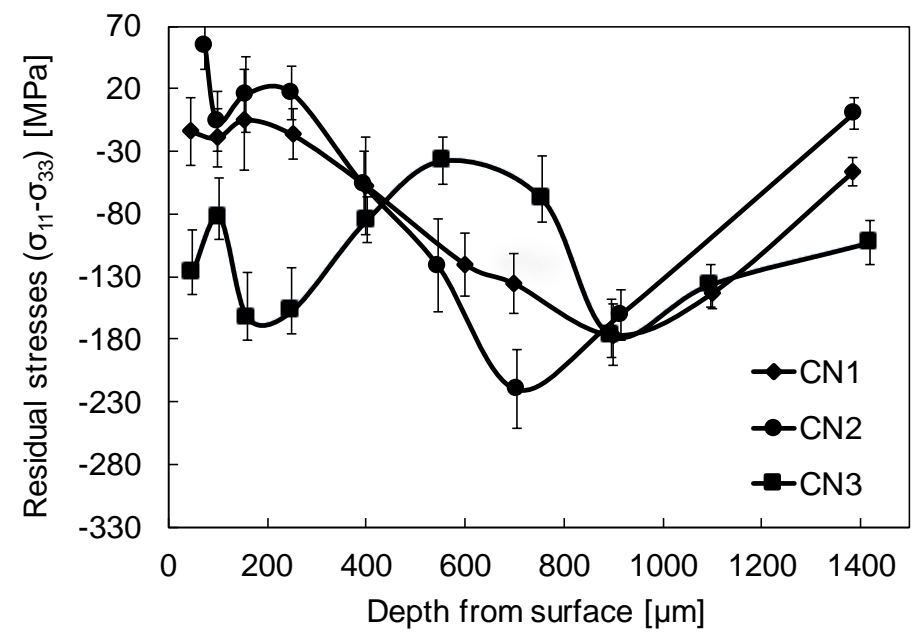

Figure 9: Effect of tempering process at $170{ }^{\circ} \mathrm{C}$ for 2 hours on the magnitudes and distribution of residual stresses for three carbonitriding conditions. 


\section{Conclusion}

This work investigated the influence of carbonitriding on phase composition, residual stresses and related properties in $20 \mathrm{MnCr} 5$ low alloy steel considering three different carbon and nitrogen potentials. After carbonitriding, the case microstructures are characterized by varying fractions of retained austenite, plate martensite and grain boundary oxidations. The maximum fractions of retained austenite which occur at a depth of $50 \mu \mathrm{m}$ from the surface highly depend on the levels of carbon and nitrogen contents reached. The maximum fraction of retained austenite at the surface affects considerably the surface hardness. The hardness decreases with increasing retained austenite contents. In contrary, the maximum hardness which varies between 700 and 730 HV1 seems to be less affected by the contents of retained austenite at the surface. In all cases, the core hardness remains relatively constant at $450 \mathrm{HV} 1$. In as-quenched state, martensite phase is essentially in compressive residual stress state. The magnitudes of compressive residual stress in martensite phase at the surface are considerably affected the fractions retained austenite and vary between -50 and $120 \mathrm{MPa}$. The peak compressive residual stresses vary between -200 and -280 MPa and occur in the range of 30 to $60 \%$ of the total case depth $(\approx 1500 \mu \mathrm{m})$ where the proportion of martensite to austenite is about $80 \%$. Increasing the fraction of retained austenite in the case shifts the location of peak compressive toward the case/core interface. Tempering of carbonitrided parts relaxes significantly the residual stresses in martensite phase and relaxation of up to $210 \mathrm{MPa}$ is reached.

\section{References}

Chongkim K 1982 Adv. X-Ray Anal. 25: 43-53.

Davies R and Smith CG 1978 A practical study of the carbonitriding process. Metal Progress 114(4): 40-53.

Davis JR and Davis \& Associates (Eds) 2002 Surface Hardening of Steel: Understanding the Basics, ASM International, USA.
Eigenmann B and Macherauch E 1996 Röntgenographische Untersuchung von Spannungszuständen in Werkstoffen. Teil III. Fortsetzung von Matwiss. und Werkstofftechn. Heft 3/1995, S. 148-160 und Heft 4/1995, S. 199-216. Mat.-wiss.u. Werkstofftech 27: 426-437.

Herring DH 2011 Carbonitriding of Fasteners. Fastener Technol. Int. 34(3): 52-54.

Katemi RJ, Epp J, Hoffmann F and Steinbacher M 2014a Characterization of Carbonitrided 18CrNiMo7-6 Steel. Int. Conf. Mechan. Industr. Eng. 3: 170-175.

Katemi RJ, Epp J, Hoffmann F and Steinbacher M 2014b Investigations of residual stress distributions in retained austenite and martensite after carbonitriding of low alloy steel. Adv. Mater. Res. 996: 550-555.

Katemi RJ and Epp J 2019 Influence of tempering and cryogenic treatment on retained austenite and residual stresses in carbonitrided 18CrNiMo7-6 Low Alloy Steel. Tanz. J. Eng. Technol. 38: 71-82.

Mittemeijer EJ, van Gent A and van der Schaaf PJ 1986 Analysis of transformation kinetics by non-isothermal dilatometry. Metall. Trans. A 17A: 1441-1445.

Parrish G 1999 Carburizing: Microstructures and properties. ASM International, USA.

Sastry CN, Khan KH and Wood WE 1982 Mechanical stability of retained austenite in quenched and tempered AISI 4340 steel. Metall. Trans. A 13A: 676-680.

Totten T, Howes M and Inoue T (Eds) 2002 Handbook of Residual Stress and Deformation of Steel. ASM International, USA.

Winter KM 2013 Independently controlled carbon and nitrogen potential: A new approach to carbonitriding process. $J$. Mater. Eng. Perform. 22(7): 1945-1956.

Young RA 1993 The Rietveld Method, Oxford University Press, New York, USA. 